\title{
INSTRUCCIONES PARA LOS AUTORES
}

Envío de Manuscritos

Los manuscritos enviados a la Revista Argentina de Anatomía Clínica deberán ser inéditos. No se considerará para publicación ningún artículo que ya haya sido publicado o esté a consideración para ser publicado por otra entidad. Los autores deberán proveer una declaración que claramente establezca esta condición y si existen conflictos de interés. Los manuscritos deben ser enviados electrónicamente, utilizando los recursos "online" que provee este sitio web. Proporcione una dirección de correo electrónica válida y que usted controle regularmente, ya que esta será la vía que utilizaremos para contactarnos. Al recibir su manuscrito, enviaremos una notificación. Si no le llegase un e-mail de confirmación, por favor, contáctese con nosotros. Envíe el texto del manuscrito en un solo archivo y las figuras en archivos separados. Controle que su manuscrito se ajuste a las normas establecidas y proporcione la información requerida del autor responsable o de referencia. Luego de ser aceptado un artículo y para efectivizar la publicación, el/los autor/es deberán firmar la transferencia de los derechos de autor a la Asociación Argentina de Anatomía Clínica. El Director y el Consejo Editorial se reservan el derecho de rechazar aquellas presentaciones que no se ajusten a las normas establecidas en las presentes instrucciones. El Director y el Consejo Editorial se reservan el derecho a adjudicar el orden y oportunidad de publicación que les parezca más acorde a los intereses de los lectores. Categoría de los Artículos

1) Contribuciones originales: Trabajos de investigación originales sobre temas de Anatomía Clínica o Educación relativa a la Anatomía.*

2) Variaciones Anatómicas: Descripción de nueva variación anatómica o aporte de nuevos elementos que representen variaciones. Serán manuscritos cortos, concisos y bien documentados. No llevará subtítulos. *

3) Presentación de casos: donde se evidencien aspectos clínicos y anatómicos. Máximo: 2000 palabras. No podrán tener más de dos autores.*

4) Temas en revisión: Revisión y actualización de temas.*

5) Una mirada atrás: Artículos cortos relativos a la historia de la Anatomía.*

6) Bases para la Clínica: Bases anatómicas para la interpretación o el desarrollo de la patología, el diagnóstico y el tratamiento clínico-quirúrgico.*

7) Temas de debate: Presentación de un tema controvertido tratado por varios comentaristas. El tema en discusión debe estar claramente explicitado.*

8) Cartas al editor: Cartas breves, cuyo contenido consistirá en un comentario sobre algún artículo publicado. Los conceptos deberán estar debidamente fundamentados. Máximo 250 palabras. Se remitirá a los autores del trabajo, y la respuesta será publicada conjuntamente con la carta.

9) Resúmenes: Se publicarán resúmenes de trabajos presentados en Congresos y otros eventos científicos.

*Artículos que se someterán a arbitraje externo.

Preparación del manuscrito

La Revista Argentina de Anatomía Clínica solicita a los autores proponer, al menos, un árbitro calificado, incluyendo su cargo, ámbito académico de trabajo y dirección de correo electrónico. El manuscrito deberá presentarse en tamaño de papel A4, en Word 2000, tipiado a doble espacio, con márgenes de $2,5 \mathrm{~cm}$ en cada lado, fuente Times New Roman 12 . Las páginas se numerarán comenzando por la página del Título. Se utilizará la Nómina Anatómica Internacional (1998- Stutgart), en latín o en su traducción al español o al inglés, según corresponda. No utilice abreviaturas al iniciar una frase. Se cuidará la gramática y redacción, tanto en castellano como en inglés. Las siglas deberán ser debidamente explicitadas en el texto previo a su utilización. La palabra "Figura" sólo podrá abreviarse cuando se haga una cita entre paréntesis (Fig. 2). Escriba los números en palabras cuando estén al inicio de una frase. Las medidas de tiempo, peso y tamaño se colocaran en números arábigos. Para las medidas de peso, tamaño, distancia, etc. se utilizará el sistema métrico decimal.El manuscrito debe tener un estilo uniforme y ser enviado tal como el autor desea que aparezca en la publicación. Podrá estar redactado en castellano o en inglés. Deberá constar de:

TÍTULO

RESUMEN

TEXTO: Introducción

Material y Método

Resultados

Discusión

Declaraciones: Conflicto de Interés. Financiamiento. Aprobación Ética. Consentimiento Informado. Contribución.

BIBLIOGRAFÍA

AGRADECIMIENTOS

TABLAS y GRÁFICOS

LEYENDAS

Comience cada subdivisión en una nueva página.

Título

Es la primera página del manuscrito y debe incluir:

a) Título completo en español

b) Título completo en inglés

c) Tipo de artículo (P/ej: comunicación original, presentación de casos, etc.)

d) Nombre de los autores (Primer nombre, inicial del segundo nombre y apellido).

e) Institución de la cual proviene el artículo. En caso que participen más de una institución, los autores pertenecientes a la misma se identificarán con un número ${ }^{1}$, que corresponderá con el número asignado a la institución.

f) Título abreviado.

g) Datos del autor de referencia (Nombre, domicilio, números de teléfono y fax, dirección de correo electrónico). Con esta persona se contactará la Editorial. De estos datos, el domicilio y el correo electrónico serán citados con la publicación.

Resumen

El resumen debe contener un máximo de 250 palabras, y sintetizar el contenido del trabajo. Debe especificar, brevemente, los objetivos, material y método, los resultados obtenidos y las conclusiones. Será suficientemente claro como para brindar una orientación al lector. Al finalizar el resumen, deben especificarse las palabras clave. Constarán de un número inferior a 100 caracteres (incluyendo espacios), y no repetirán términos utilizados en el título. 
El Resumen se presentará en Castellano y en Inglés.

Declaraciones:

Conflicto de interés/es: Se declarará si existe o no. De existir, se especificará el tipo (ver página principal del sitio web).

Financiamiento: Incluir fuente de financiamiento

Aprobación ética: Si corresponde, especificar la entidad que la realizó.

Consentimiento informado: En los casos que se requiera (casos clínicos, presentaciones que involucren seres vivos o que puedan ser identificados en la publicación, etc.)

Contribución: Se especificará la tarea desarrollada por cada autor.

Bibliografía

La bibliografía que se incluya deberá haber sido citada en el texto y ordenarse por orden alfabético según el apellido del primer autor.

Las citas bibliográficas en el texto deberán contener, entre paréntesis, el año de publicación o el nombre del autor y el año de publicación (separados por coma) cuando el autor no hubiera sido mencionado por nombre en el texto.

Por ejemplo: ... según XXXX (2000)

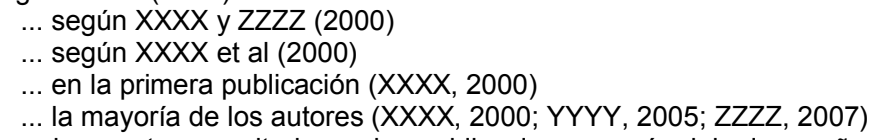

Cuando un mismo primer autor sea citado en dos publicaciones o más del mismo año, se le asignará una letra (a, b, c, etc.) a cada una, según el orden alfabético del apellido del segundo autor.

Por ejemplo: ... según XXXX (2000a)

...según XXXX (2000a, b)

En la Bibliografía, se colocará la letra inmediatamente después del año. La Bibliografía empleará las abreviaturas de los nombres de las Revistas utilizadas en el Index Medicus. La cita de artículos en publicaciones periódicas será del siguiente modo:

Nombre del autor o autores, año de publicación: Título del Artículo. Abreviatura de la Revista, volumen: páginas correspondientes a la publicación.

Ej.: Nightingale SS, Western P, Hutson JM. 2008. The migrating gubernaculum grows like a "limb bud". J Pediatr Surg 43: 38790.

La cita de libros incluirá: Nombres de los autores, año de publicación, título del libro, lugar de publicación, editorial, páginas involucradas o total de páginas.

Ej.: Latarjet M, Ruiz Liard A. 1989. Anatomía Humana. 2a Edición, México: Editorial Médica Panamericana, pag: 1-1825.

Citas con componentes variables: Nombre del editor, año de publicación, título del capítulo, título del libro, volumen/edición, lugar de publicación, editorial, páginas involucradas o total de páginas.

Ej.: Whitehouse GH, Worthington BS. (eds.) 1996. Techniques in diagnostic imaging. 2nd Ed. Oxford: Blackwell Science. 526 p. Referencias de internet: Nombre del autor, año, título del artículo, URL: dirección de internet (mes y año de acceso).

Ej.: Goodwin H. 2002. Review of general and vascular surgery claims. URL: http://www.themdu.com/hospital/advice (accessed November 2004).

Agradecimiento/s:: Se podrá incluir aquellas personas o entidades que hayan actuado favoreciendo o colaborando con el trabajo o la publicación. Recomendamos el agradecimiento a los donantes de cadáveres para la docencia e investigación.

Tablas y Gráficos

Las tablas y gráficos deben estar citadas en el texto y tener título. El título debe ser breve pero representativo del contenido. Serán simples, para que se puedan visualizar con claridad. En el manuscrito se colocarán después de las leyendas de las figuras. Se limitará a 1 (uno) el número de tablas o gráficos que se incluyan sin cargo.

Figuras

Todas las figuras deben ser citadas en el texto y tener leyenda. Se limitará a 3 (tres) el número de figuras que se incluyan sin cargo. La cantidad de figuras superior a tres tendrá un cargo de u\$s 20 por cada una (la mitad, si todos los autores son miembros de la AAAC). Se enviarán como archivos separados del texto, cada figura en un archivo JEPG o GIF. El archivo debe ser denominado con el número de la Figura. Las figuras deben ser archivos de alta resolución, para asegurar la calidad de la publicación. Las leyendas se incluirán en el archivo principal, a continuación de la Bibliografía y antes de las Tablas y Gráficos, según corresponda. Los editores o revisores podrán solicitar las imágenes originales.

Todas las ilustraciones deben ser enviadas en su forma, tamaño y características definitivas, tal como serán publicadas. Podrán tener $16 \mathrm{~cm}$ de ancho (página completa) o $7,75 \mathrm{~cm}$ de ancho (una columna).

Las ilustraciones deberán tener un contraste adecuado; y cuando se incluya más de una imagen en la misma figura, deberán tener la misma densidad y tono para evitar la pérdida de calidad. Resolución mínima: 300 ppi.

Los dibujos serán en negro, con máximo contraste. Evitar el lápiz, acuarela o aerógrafo. Deberán tener una resolución mínima de 600 ppi.

Copia de prueba

Previo a la publicación, se le enviará una copia de prueba al autor de referencia. Cualquier corrección deberá ser marcada claramente y devuelta de inmediato. Si en el lapso de tiempo de una semana no se hubiera regresado la copia de prueba al Director de la Revista, con las correcciones efectuadas, se publicará sin modificaciones.

Copia

Al autor de referencia del manuscrito publicado se le enviará la versión informática tal como aparece en la publicación.

Arbitraje

Los manuscritos serán sometidos a revisión por parte de árbitros externos al Consejo Editorial de la Revista. La resolución de aceptación de los manuscritos para publicación o rechazo dependerá del resultado del arbitraje.

Por información adicional contactarse a:

Prof. Dra. Susana N. Biasutto

Obispo Trejo $1180.1^{\circ} \mathrm{E}$

5000 - Córdoba

Argentina 